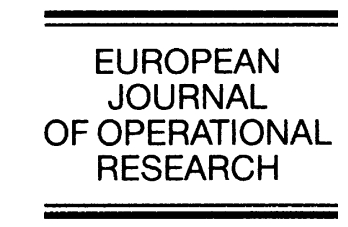

www.elsevier.com/locate/dsw

Interfaces with Other Disciplines

\title{
Static hedging of multivariate derivatives by simulation
}

\author{
P. Pellizzari * \\ Department of Applied Mathematics, University of Venice, DD 3825/E, 30123 Venice, Italy
}

Received 28 January 2002; accepted 24 February 2004

Available online 11 May 2004

\begin{abstract}
We propose an approximate static hedging procedure for multivariate derivatives. The hedging portfolio is composed of statically held simple univariate options, optimally weighted minimizing the variance of the difference between the target claim and the approximate replicating portfolio. The method uses simulated paths to estimate the weights of the hedging portfolio and is related to Monte Carlo control variates techniques. We report numerical results showing the performance of this static hedging procedure on bivariate options on the maximum of two assets and on 2- and 7dimensional portfolio options. It is shown that, in the presence of transaction costs, Value at Risk and Expected Shortfall of the dynamically hedged positions can be higher than the ones obtained by a static hedge.
\end{abstract}

(c) 2004 Elsevier B.V. All rights reserved.

Keywords: Option hedging; Risk management; Monte Carlo simulation; Control variates

\section{Introduction}

Arbitrage pricing theory can be used to obtain the market value of complex derivatives. If arbitrages are ruled out and a replicating portfolio exists then its cost must be equal to that of the contingent claim. The famous Black-Scholes (BS) pricing formula is based on arbitrage arguments and explicitly provide a delta-based hedging strategy to replicate a plain put/call option. However the success is not guaranteed as continuous time rebalancing of the hedging portfolio is in order. On one side this is practically infeasible forcing the hedger to discretize the strategy and on

\footnotetext{
${ }^{*}$ Tel.: +39-41-234-6924; fax: +39-41-522-1756.

E-mail address: paolop@unive.it (P. Pellizzari).
}

the other the situation is worsened if transaction costs are taken into account. A substantial research effort has tried to solve some of the problematic aspects of practical derivatives hedging. Boyle and Emanuel (1980) is an early paper that deals with discretization error in implementing the Black-Scholes strategy. Leland (1985) proposes a discrete modified BS-type strategy that allows in the limit (but see also Kabanov and Safarian, 1997) to replicate the claim allowing for transaction costs. This is obtained by inflating the volatility of the stock that in turn forces to charge a bigger price to the buyer and to reduce the weight of the required rebalacings. Leland's paper shows that quite often the hedger need $10-20 \%$ of the BS claim price to be able to fulfill his obligations. Another impressive illustration of the difficulties arising in concrete option hedging is in (Green and 
Figlewsky, 1999), that shifts the attention on model risk. It is argued that BS model might be inappropriate for a variety of reasons, the most investigated being probably the estimation and modelization of the volatility of the underlying stock. The paper shows that huge risk is involved in practical option hedging. This is true also when extreme care is used to estimate volatilities or when realized ex post volatility is (unfairly) plugged into the strategy. Moreover, inflating the volatility up to $50 \%$ of the calculated estimate, reduces the mean loss but is less useful to reduce extreme shortfalls.

Other papers (Derman et al., 1995; Carr et al., 1998) describe a different paradigm, named static hedging. If the claim is statically redundant, then it exists a portfolio of traded assets that replicates the target payoff without the need to rebalance in continuous time. A very simple example is given by the put/call parity equation, that can be trivially employed to hedge a call (put) option by a portfolio in the stock and in a put (call) option. It is of course not always possible to find such a simple solution, but Derman et al. (1995) shows how to approximately hedge a barrier claim using plain options with different strikes and maturities. This approximation is exact solely on the nodes of a binomial tree that models the underlying dynamics but nevertheless the static hedging that is obtained has no extra cost besides the initial purchase.

Recent work by Ben Ameur et al. describes a partial hedging technique, that actually hedges a 'portion' of the claim. This can be done when the amount needed for a perfect hedge is not available or the agent prefers to use only a fraction of the price for hedging purposes (Ben Ameur et al., 2001). Of course some default risk is introduced and it is understood that, should the hedging portfolio fail to provide the required sum, the agent is resorting to other resources to fill the gap. An example, in the case of a European call option, is given by a knock out option with the same strike that will hedge the claim only if the terminal stock price is below the knockout barrier. Needless to say, this is a cheap but risky way to hedge against risk and it turns out that this behavior is coherent with a risk-seeking agent (Follmer and Leukert, 1999). In a more recent paper (Follmer and Leuk- ert, 2000) it is shown how to optimally hedge a contingent claim minimizing, under a budget constraint, the expected shortfall weighted by a loss function that depends on the risk attitude of the agent. It is shown that the optimal solution is to hedge a modified claim, that in the case of a European call smoothly varies from the knockout option in the risk-seeking case to a call with a bigger strike for the most risk averse agent. Note that the idea of hedging a modified claim is also exploited for the apparently different purpose of reducing the effects of misspecified models (Ahn et al., 1997).

While the previous mentioned works all deal with univariate options, it is obvious that properly hedging is difficult to obtain for multivariate options as well. Indeed, there are reason to believe that, as each rebalancing requires the adjustment of multiple assets in the hedging portfolio, the effect of transaction costs and discretization might be amplified. As far as we know, this multivariate hedging problem has received much less attention than the univariate one, probably for the difficult analytical treatment that is required.

In this paper we describe a way to approximately hedge a multivariate derivative by the minimization of the variance of the discrepancy between the payoffs and the revenues of a static portfolio. This static hedging procedure is very simple but generally underperforms dynamic hedging if transaction costs are low.

We show that this method is related to a recent variance reduction method for Monte Carlo option pricing, known as mean Monte Carlo (MMC) (Pellizzari, 2001). The paper (Avellaneda et al., 2000) describes a very interesting way to calibrate a Monte Carlo simulation to obtain exact pricing of some benchmark instruments and contains ideas similar to ours. However, the setting is different in that Avellaneda and coauthors still focus mainly on pricing of univariate claims.

In detail, Section 2 presents an example of a portfolio option on two assets clarifying the differences among various hedging methods. It is apparent that, if perfect hedging is practically unattainable or too costly, then approximate static hedging can be useful. In Section 3, the MMC method is briefly covered in order to show that it can be fruitfully interpreted in terms of static 
hedging and the extension is discussed. We then present a pricing numerical comparison on bivariate options analyzed in (Boyle, 1988) where an extension of the binomial approach of Cox-RossRubinstein to the case of two risk sources is developed. Some 2- and 7-dimensional portfolio options are also analyzed with emphasis on downside risk using Value at Risk and Expected Shortfall. Finally, Section 5 contains some concluding remarks.

\section{A worked example}

Suppose you are asked to write an European option on a basket of two risky lognormal stocks whose dynamics is described by

$\mathrm{d} S_{i}=r S_{i} \mathrm{~d} t+\sigma S_{i} \mathrm{~d} Z_{i}, \quad i=1,2$,

where $r, \sigma_{1}, \sigma_{2}$ are constants and $Z_{1}, Z_{2}$ are standard Brownian motions. We denote the values of the assets at time $t$ by $S_{1 t}, S_{2 t}$ for $0 \leqslant t \leqslant T$. The payoff at expiration is

$f\left(S_{1 T}, S_{2 T}\right)=\max \left(S_{1 T}+S_{2 T}-k, 0\right)$.

Assume we set the initial prices $S_{10}=S_{20}=100$, volatilities $\sigma_{1}=0.3, \sigma_{2}=0.2$, correlation between returns is $\rho=0.5$, maturity $T=1$ year, strike price $k=190$ and riskless rate $r=0.1$ (continuously compounded).

As there is no analytic valuation formula for such asset, a preliminary Monte Carlo simulation is performed using 100 replications obtaining the price $\hat{C}_{\mathrm{MC}}=33.89$ equipped with sample standard deviation $\hat{\sigma}_{\mathrm{MC}}=3.26$. Note that 100 simulations are clearly too few to obtain reasonable precision but our main point is totally independent of the number of replicates.

Next, in order to lower the huge standard deviation just quoted, another more refined method (see Pellizzari, 2001, or the review in the following section) is used to get more accurate mean Monte Carlo (MMC) price $\hat{C}_{\mathrm{MMC}}=33.34$ with standard deviation $\hat{\sigma}_{\mathrm{MMC}}=0.40$ (again 100 simulations are used). The standard deviation is reduced by $88 \%$, which is per se an important achievement. However, this encouraging picture still does not take into account other useful fea- tures. In particular the method also reports that the following portfolio of simple call options can be used to (partially) hedge the basket option payoff: consider at $t=0$ a long position in 0.96 call options on the first asset and 1.01 call options on the second, being respectively 94.88 and 89.71 the strike prices. In order to get this portfolio an additional 5.59 must be borrowed in $t=0$ and paid back with interest at maturity.

This compound portfolio allows to have at maturity a random sum that can be used to 'hedge' the random payoff of basket option (1). In fact the net difference between the payoff of the basket option and the value of the 'hedging' portfolio is on average null with standard deviation $\exp (r T) \hat{\sigma}_{\mathrm{MMC}} \sqrt{100}=4.4$. Note that the standard deviation of the option payoff is about 36 , hence using the previously mentioned 'hedging' portfolio has reduced the risk by a factor of about 8 .

Let us rephrase the whole experiment as follows: once you write an option you get the price and commit to the subsequent liability. The two extreme choices are no hedging at all and deltahedging. On one side we envision huge final risk as the average final net payment is null, but the standard deviation, computed with the risk neutral density, is 36 . On the other side it is well known that delta-hedging is imprecise and, more importantly, expensive in a realistic situation. There is a third possible solution, based on the previously described portfolio, that partially hedges the option payoff leaving a risk (measured as standard deviation of the net cashflow) of 4.4. Table 1 sums up the situation.

This example (together with many others we could select) shows that the lower variance obtained using MMC comes together with information that can be used to build a static portfolio that partially hedges the liability leaving a residual risk whose standard deviation is, up to a constant, the same of the sample price. Hence, if low variance is obtained in the enhanced Monte Carlo simulation, then low risk is associated to the static hedging portfolio. As far as we know, there is no other example of variance reduction technique that has a financial interpretation in terms of static hedging. In the following section we briefly review MMC and describe this static interpretation. 
Table 1

The hedging performance of different methods are shown

\begin{tabular}{llccll}
\hline Method & Hedge & Risk $(\sigma)$ & Risk reduction $(\%)$ & Cost & Hedging portfolio \\
\hline MC & None & 36.0 & 0 & None & None \\
Static & Partial & 4.4 & 88 & Low & Static, 2 calls \\
Dynamic & Perfect & 0 & 100 & High & Dynamic, Delta-based \\
\hline
\end{tabular}

The 'Risk' column provides the standard deviation of the net cashflows (whose mean is approximately null) at maturity. In the 'Risk Reduction' column we report the reduction in standard deviation with respect to the no hedging (MC) situation. The final two columns contain a rough description of the cost of the hedging strategy and of the hedging portfolio.

\section{Mean Monte Carlo and approximate static hedging}

In this section we describe the mean Monte Carlo method extending its capabilities by optimally selecting some parameters that affect the variance. This procedure is equivalent to (partially) hedge the claim using a portfolio of simple assets. If the residual risk is deemed appropriate or can be reduced to a suitable level, the static portfolio can be employed in place of complex dynamic hedging procedures.

Referring the reader to Pellizzari (2001) for a detailed treatment, we describe the main ideas behind MMC. Assume we want to price at time $t=0$ an European option on $n$ stocks that pays the sum

$f\left(S_{1 T}, \ldots, S_{n T}\right)$,

at maturity $T$, where $S_{i t}, 0 \leqslant t \leqslant T, 1 \leqslant i \leqslant n$, denotes the value of $i$ th asset at time $t$ and the dynamic of each asset is described by

$\mathrm{d} S_{i}=r S_{i} \mathrm{~d} t+\sigma_{i} S_{i} \mathrm{~d} Z_{i}$,

where $r$ is the instantaneous riskless rate, $\sigma_{i}$ is the volatility and $Z_{i}$ is a standard Brownian motion such that $\operatorname{Cor}\left(Z_{i}, Z_{j}\right)=\rho_{i j}$. The MMC method exploits a set of control variates (see Rubinstein, 1981; Bratley et al., 1987) obtained by plugging into (2) the known means $E\left[S_{i T}\right]$ to replace the random $S_{i T}$ for all $i$ 's but one. The $j$ th control variate $(1 \leqslant j \leqslant n)$ is given by

$$
\begin{aligned}
M_{T}(j)= & f\left(E\left[S_{1 T}\right], \ldots, E\left[S_{j-1, T}\right],\right. \\
& \left.S_{j T}, E\left[S_{j+1, T}\right], \ldots, E\left[S_{n T}\right]\right) .
\end{aligned}
$$

The above definition matches the two requirements of a control variate, namely non-null correlation with (2) and easy analytical valuation of the mean of (3). Technically, the replacement of $n-1$ expectations in the payoff is used to reduce the dependence of (2) to one risk source alone, allowing most often to apply standard pricing methods to the resulting univariate payoff. Observe that there is no guarantee that $E\left[M_{T}(j)\right]$ will be known in close form for every conceivable payoff profile $f$. However, even if numerical approximations should be used to solve the univariate integral for $E\left[M_{T}(j)\right.$, there are extremely accurate methods (e.g., Gaussian quadrature) for univariate problems, see Krommer and Ueberhuber (1998) for a comprehensive account and Schmeiser et al. (forthcoming) for an application to control variates.

The estimate of the price is then obtained by taking the discounted average of many random payoffs

$f\left(S_{1 T}, \ldots, S_{n T}\right)-\sum_{i=1}^{n} \hat{b}_{i}\left(M_{T}(i)-E\left[M_{T}(i)\right]\right)$,

where $\hat{\mathbf{b}}=\left(\hat{b}_{1}, \ldots, \hat{b}_{n}\right)$ is a vector of estimated coefficients chosen to minimize the variance.

A moment of reflection shows that variance reduction is achieved using a combination of assets whose final payoff is given by the $M_{T}(j)$ 's. Recall the example of Section 2, where we have

$$
\begin{aligned}
& M_{T}(1)=\max \left(S_{1 T}+E\left[S_{2 T}\right]-k, 0\right), \\
& M_{T}(2)=\max \left(E\left[S_{1 T}\right]+S_{2 T}-k, 0\right),
\end{aligned}
$$

noting that the basket payoff is mimicked by a portfolio made of one call option on asset $S_{1}$ (having strike price $k_{1}=E\left[S_{2 T}\right]-k$ ) and one call option on asset $S_{2}$ (having strike $k_{2}=E\left[S_{1 T}\right]-k$ ). Thus, if the variance reduction is effective, i.e. the standard deviation of (4) is small, then the payoff of the portfolio of the two calls is close to that of 
the basket option. This is tantamount to say that an approximate static hedging portfolio has been obtained selecting a combination of plain call options. This optimal selection of control variates can directly be interpreted in terms of approximate static hedging as discussed in the sequel.

The previous description of the MMC method can be used to propose a straightforward generalization based on the search of a hedging portfolio by minimization of the variance of the net difference of the option payoff and the value of the hedging portfolio. Assume we can build a hedge choosing among the assets in the set

$H=\left\{H_{1}, \ldots, H_{p}\right\}$,

where each $H_{i}, i=1, \ldots, p$, is a payoff function (at maturity $T$ ), typically depending on some underlying stock $S_{j}, j=1, \ldots, n$. The set $H$ should contain liquid assets (for low trading costs) that span a wide payoff space. Some reasonable examples of such set $H$ will be described soon. Then we can approximately hedge the option (2) by solving the minimization problem

$$
\begin{aligned}
& \min _{b_{0}, b_{1}, \ldots, b_{p}} \operatorname{Var}\left[f\left(S_{1 T}, \ldots, S_{n T}\right)-b_{1} H_{1}-b_{2} H_{2}\right. \\
& \left.\quad-\cdots-b_{p} H_{p}-b_{0}\right]
\end{aligned}
$$

in the cash amount (at maturity) $b_{0}$ and in the quantities $b_{1}, \ldots, b_{p}$ that are held in each $H_{i}$. We typically expect $p$ to be much smaller than $N$, as the former is about of the same size as $n$, the number of risk sources, while the latter is at least in the thousands. This also ensures that few control variates are used with respect to the number of simulations, as suggested in Nelson (1990) or Lavenberg and Welch (1981).

If the payoff and the assets in $H$ are $(p+1)$-dim multivariate normal, then the $\hat{b}_{i}$ 's are obtained by regressing $f\left(S_{1 T}, \ldots, S_{n, T}\right)$ on the vectorial subspace $\mathscr{L}\left(H_{1}, \ldots, H_{p}\right)$, to get the theoretical minimizers $\left(b_{0}^{*}, b_{1}^{*}, \ldots, b_{p}^{*}\right)$. The normality assumption can be grossly violated in a pricing framework as the payoff density is likely to have positive mass at 0 (especially in the case of out-of-the-money options). However, Theorem 3 in Nelson (1990) points out that, if the sample size $N \rightarrow \infty$, then $\hat{b}_{i} \rightarrow b_{i}^{*}$, hence justifying the use of least squares estimation in the case of large sample size. This approach, consistently used in Pellizzari (2001), provides good results for a variety of payoffs of different type and dimensionality.

Some examples of the set $H$ are described below, together with the specification of the minimization problem to solve. For simplicity, we omit the constant term $b_{0}$ in the minimization problem, we assume $n=2$ and still refer to the problem to approximately hedge the payoff of the example in Section 2.

1. $H=\left\{\max \left(S_{1 T}+E\left[S_{2 T}\right]-k, 0\right)\right.$, $\left.\max \left(S_{2 T}+E\left[S_{1 T}\right]-k, 0\right)\right\}$.

This is a restrictive situation, corresponding to MMC, where we hedge using solely two call options with given strike prices. The minimization problem is

$$
\begin{aligned}
& \min _{b_{1}, b_{2}} \operatorname{Var}\left[f\left(S_{1 T}, S_{2 T}\right)-b_{1} \max \left(S_{1 T}+E\left[S_{2 T}\right]-k, 0\right)\right. \\
& \left.\quad-b_{2} \max \left(S_{2 T}+E\left[S_{1 T}\right]-k, 0\right)\right] .
\end{aligned}
$$

2. Assume we can hedge selecting the strike prices $a$ 's: then we have that

$H=\left\{\max \left(S_{1 T}-a_{1}, 0\right), \max \left(S_{2 T}-a_{2}, 0\right)\right\}$.

It is obvious that more flexibility in the hedging strategy is allowed and the corresponding minimization problem is

$$
\begin{aligned}
& \min _{b_{1}, b_{2}, a_{1}, a_{2}} \operatorname{Var}\left[f\left(S_{1 T}, S_{2 T}\right)-b_{1} \max \left(S_{1 T}-a_{1}, 0\right)\right. \\
& \left.\quad-b_{2} \max \left(S_{2 T}-a_{2}, 0\right)\right] .
\end{aligned}
$$

3. Why should we hedge using options alone? If we set

$$
\begin{aligned}
H= & \left\{\max \left(S_{1 T}-a_{1}, 0\right),\right. \\
& \left.\max \left(S_{2 T}-a_{2}, 0\right), S_{1 T}, S_{2 T}\right\}
\end{aligned}
$$

then better approximate replication can be obtained as stocks themselves can be used. The minimization problem becomes

$$
\begin{aligned}
& \min _{b_{1}, b_{2}, b_{3}, b_{4}, a_{1}, a_{2}} \operatorname{Var}\left[f\left(S_{1 T}, S_{2 T}\right)-b_{1} S_{1 T}-b_{2} S_{2 T}\right. \\
& \left.-b_{3} \max \left(S_{1 T}-a_{1}, 0\right)-b_{4} \max \left(S_{2 T}-a_{2}, 0\right)\right] .
\end{aligned}
$$

4. In realistic situations it might be that only some strikes are available in the option market. Assume for example that only calls written at strikes $90,100,110$ on $S_{1}$ and $S_{2}$ can be 
purchased, in such a way that just specific out, at and in-the-money options are eligible. Then the set $H$ is

$$
\begin{aligned}
H= & \left\{\max \left(S_{1 i}-90,0\right), \max \left(S_{1 i}-100,0\right),\right. \\
& \left.\max \left(S_{1 i}-110,0\right), S_{i T}\right\},
\end{aligned}
$$

where $i=1,2$ and the variance is minimized with appropriate choice of the eight variables $b_{i}^{(90)}, b_{i}^{(100)}, b_{i}^{(110)}, b_{i}, i=1,2$, denoting the quantities held in the call 90 , call 100 , call 110 (written on each assets) and in the two stocks $S_{1}$ and $S_{2}$, respectively. Formally, the optimization problem is

$$
\begin{aligned}
& \min \operatorname{Var}\left[f\left(S_{1 T}, S_{2 T}\right)-b_{1} S_{1 T}-b_{2} S_{2 T}\right. \\
& \quad-b_{1}^{(90)} \max \left(S_{1 T}-90,0\right) \\
& \quad-b_{2}^{(90)} \max \left(S_{2 T}-90,0\right) \\
& \quad-b_{1}^{(100)} \max \left(S_{1 T}-100,0\right) \\
& \quad-b_{2}^{(100)} \max \left(S_{2 T}-100,0\right) \\
& \quad-b_{1}^{(110)} \max \left(S_{1 T}-110,0\right) \\
& \left.-b_{2}^{(110)} \max \left(S_{2 T}-110,0\right)\right]
\end{aligned}
$$

where minimization is performed on the aforementioned eight variables.

These examples are of course not exhaustive (for example, an exchange option on the two assets is indeed useful to further reduce risk) but show how approximate hedging can be built in different frameworks.

It is obvious that functionals other than the variance could be minimized. There are however some reasons to prefer the simple quadratic approach of the variance. On one side this choice allows to interpret the procedure as a Monte Carlo method with control variates. On the other hand, the estimation of the parameters is done in the quadratic framework by least squares and, if $\mathbf{b}$ alone is to be estimated, only OLS is required to build the static portfolio. Note also that the variance minimization problem is in full generality non-differentiable, due to the possible lack of smoothness of the payoff function $f$.

Finally, though not used in the following, we note that problem (6) can be generalized as follows:

$$
\begin{array}{cc}
\min _{b_{0}, b_{1}, \ldots, b_{p}} & \operatorname{Var}\left[f\left(S_{1 T}, \ldots, S_{n T}\right)-b_{1} H_{1}-b_{2} H_{2}\right. \\
& \left.-\cdots-b_{p} H_{p}-b_{0}\right] \\
\text { subject to: } & g_{i}\left(b_{1}, \ldots b_{p}\right) \geqslant 0, i=1, \ldots, m .
\end{array}
$$

Constrained Monte Carlo is a recent research area: both Szechtman and Glynn (2001) and Avellaneda et al. (2000) are recent papers that deal with similar frameworks, though their ideas are somewhat different. In the simplest case (normal random variables and linear constraints), the optimal $b_{i}$ 's can be estimated by constrained least squares but more theoretical and applied research is needed to clarify the potential of the generalization.

The $m$ constraints could take into account some important financial features: no borrowing and no short selling, for example, can be enforced by setting $m=p+1$ and

$g_{i}\left(b_{1}, \ldots b_{p}\right)=b_{i}, \quad i=0, \ldots, p$.

Another interesting possibility is to require the static hedging to be self-financing: assume that the $p$ assets in $H$ can be priced by Black-Scholes formulas, like in all the cases shown previously, or by numerical methods. Let now $\mathbf{C}=\left(C_{1}, \ldots, C_{p}\right)$ be the vector of the prices of the simple assets in $H$ and let $\hat{C}_{0}$ be a pilot estimate of the price of the complex derivative, for example computed by a preliminary simulation. Then the constraint

$g_{i}\left(b_{1}, \ldots b_{p}\right)=\hat{C}_{0}-\sum_{i=1}^{p} b_{i} C_{i}$,

together with $b_{0}=0$, will produce a hedge that costs at $t=0$ approximately the same amount that is cashed to write the derivative. Notice that is a very strong requirement as borrowing is totally banned. Indeed, this should make unviable the usual Black-Scholes strategy, which is almost always based on dynamic borrowing of variable amounts of cash. This point will be further clarified below.

\section{Some static hedges}

In the following section we present some practical applications of the method by pricing and 
hedging options on the maximum of two stocks and portfolio options written on multiple assets.

We first price some European call and put options on the maximum of two stocks and compare against the results obtained in (Boyle, 1988) using a bivariate lattice approach with 50 steps. This is an indirect way to assess the quality of the replication of the static hedge at maturity: if in fact the static portfolio closely matches the derivative final payoff, then its price should be extremely close to the theoretical one to avoid arbitrage opportunities. See Rebonato and Cooper (1998) for another application of the same idea. More importantly, this pricing exercise shows that the estimation of the static portfolio by simulated paths is accurate and no extra cash is on average needed to build a static hedge.

The parameters are the following: $S_{01}=S_{02}=$ $40, \sigma_{1}=0.2, \sigma_{2}=0.3, \rho_{12}=0.5, r=0.04879$ continuously compounded, $T=0.58333$ and exercise prices of 35, 40 and 45 .

Table 2 reports the result of the lattice method, analytical evaluation formulas (Stulz, 1982), the cost of the static hedging, namely $\sum_{i} b_{i} C_{i}$, composed of plain options on each of the assets (two call options for the maximum and two put options

Table 2

Comparison of $\mathrm{max} / \mathrm{min}$ option prices

\begin{tabular}{|c|c|c|c|c|}
\hline $\begin{array}{l}\text { Exercise } \\
\text { price }\end{array}$ & $\begin{array}{l}\text { Boyle } \\
\text { (1988) }\end{array}$ & $\begin{array}{l}\text { Stulz } \\
(1982)\end{array}$ & Static & $\operatorname{SD}\left[f-\sum_{i} \hat{b}_{i} H_{i}\right]$ \\
\hline \multicolumn{5}{|c|}{ European call on the maximum of two assets } \\
\hline 35 & 9.419 & 9.420 & $\begin{array}{c}9.414 \\
(0.063)\end{array}$ & 2.033 \\
\hline 40 & 5.483 & 5.488 & $\begin{array}{c}5.484 \\
(0.051)\end{array}$ & 1.615 \\
\hline 45 & 2.792 & 2.795 & $\begin{array}{c}2.792 \\
(0.034)\end{array}$ & 1.072 \\
\hline \multicolumn{5}{|c|}{ European put on the minimum of two assets } \\
\hline 35 & 1.392 & 1.387 & $\begin{array}{c}1.383 \\
(0.016)\end{array}$ & 0.525 \\
\hline 40 & 3.795 & 3.798 & $\begin{array}{c}3.792 \\
(0.035)\end{array}$ & 1.119 \\
\hline 45 & 7.499 & 7.500 & $\begin{array}{c}7.491 \\
(0.050)\end{array}$ & 1.657 \\
\hline
\end{tabular}

The results of a lattice method (Boyle, 1988), analytical evaluation formula (Stulz, 1982) and cost of static hedging are shown. The last column shows the average standard deviation of the replication error. for the minimum) and of cash, as exemplified in the example of Section 2. We report the mean and the standard deviation (in brackets) of the cost on 100 tries. The hedging parameters are estimated using 1000 simulated samples. The average value of the static portfolio is close to both the theoretical price and the lattice approximation, always showing pricing errors smaller than 1 cent. Observe, in the rightmost column, that the replication error has still a sizeable standard deviation thus pointing to residual non-hedged risk. Hence, the price of a static hedge is close to the fair price of the derivative but the risk is only reduced and not eliminated.

The following examples will compare the well known dynamic delta-hedging with the performance of a static hedging approach on portfolio options written on 2 and 7 assets. As we are mainly interested in quantifying the risk exposure, we report two popular risk measures, the Value at Risk (VaR) and the Expected Shortfall (ES). The VaR at confidence level $\alpha$ is such that

$\operatorname{Pr}\left(X \leqslant \operatorname{VaR}_{\alpha}\right)=\alpha$,

where $X$ is the replication error at maturity. We estimate $\mathrm{VaR}_{\alpha}$ by the empirical $100 \alpha$ percentile. The ES is defined as

$\mathrm{ES}_{\alpha}=E\left[X \mid X \leqslant \mathrm{VaR}_{\alpha}\right]$.

We empirically obtain $\mathrm{ES}_{\alpha}$ by sorting the realizations of $X$ and taking the mean of the smallest $\alpha$ percent of the sample. It is standard practice to compute VaR's and ES's at confidence levels $\alpha=0.01$ and $\alpha=0.05$ and we do not depart from this custom.

Consider first an European portfolio option written on two risky stocks $S_{1}, S_{2}$ with final payoff $\max \left(S_{1 T}+S_{2 T}-k, 0\right)$ and select the parameters as in the example of Section 2. We simulate ${ }^{1} 1000$

\footnotetext{
${ }^{1}$ In the following, all simulated paths are obtained using the risk neutral probability densities. It is true that hedging errors depend on the drift of the assets, but we do not provide a full set of simulations for different drift values, that are left to future research. Some experimentation performed by us shows that while the risk figures are obviously changing with drifts, the comparative picture of dynamic and static hedging is not and the final considerations apply to a broad range of drifts.
} 
Table 3

Parameters of the static hedging portfolio, with standard deviations in brackets

\begin{tabular}{lll}
\hline & Quantity & Strike \\
\hline Call on $S_{1}$ & 1.00 & 98.06 \\
& $(0.010)$ & $(0.38)$ \\
Call on $S_{2}$ & 1.01 & 89.17 \\
& $(0.006)$ & $(0.36)$ \\
Cash & -3.87 & - \\
& $(0.27)$ & - \\
\hline
\end{tabular}

stock paths, and approximatively monthly, weekly and semiweekly rebalancings of the delta-based hedging portfolios (hence 12, 60 and 120 revisions were allowed, respectively). Of course no rebalancing is performed for the static hedging strategy. There is no close formula to compute the deltas for a portfolio option and they were accurately ${ }^{2}$ evaluated by Monte Carlo simulation. The parameters of the static hedge (again composed by call options in each asset and cash) are calculated as in the above example making use of 1000 simulations and are shown in Table 3. We can see in the table that the optimal static hedging portfolio is made of 1.00 call option on $S_{1}$, with strike 98.06 , and 1.01 call options on $S_{2}$, with strike 89.17 . Both options have maturity 1 year and borrowing 3.87 is necessary at $t=0$. This amount, as described in Avellaneda et al. (2000), is the constant term $b_{0}$ in the regression used to compute the weights, discounted back at time $t=0$.

First, notice that this amount is a small fraction (about $10 \%$ ) of the price, which is about 33.34. Second, the greeks of the portfolio option $\left(\Delta_{1} \sim 0.8, \Delta_{2} \sim 0.77\right)$ show that that the initial borrowing required for starting a dynamic hedging strategy is huge (more than 120, to be compared with the above 3.27). This is typical of all deltabased hedges, almost irrespective of payoff profile and number of risk sources: you must borrow a considerable amount or use other cash at inception

\footnotetext{
${ }^{2}$ In detail, central differences and correlated Monte Carlo (common variables) are used, see Rubinstein (1981) for an introduction. This means that we evaluate the greeks using the same sequence of random numbers, thus limiting the sample noise that can deteriorate numerical derivative calculations. The resulting deltas appear to be accurate and stable.
}

of a dynamic hedge. A most practical interesting fact of static hedging might lie exactly in this small borrowing requirement.

Assuming a perfect market with no transaction costs, Table 4 compares the replication error of static and dynamic hedging portfolios. A look at the last rows shows that approximate null mean is achieved as expected, though standard deviation of the replication error is still sizeable. This is true in particular for dynamic hedging, that should (in continuous time) offer perfect risk coverage. However, due to discrete rebalancings (and possibly numerical deltas calculation) the residual risk is far from being negligible.

It is interesting to note that the maximum loss cannot exceed 4.28 because in the worst possible scenario (when both call options in the static portfolio expire out-of-the-money) $4.28=3.87 \exp (r T)$ must be paid for the initial borrowing. This bounded loss might be an additional nice feature of the static hedging for portfolio options, though the same property does not hold in the previous example for maximum/minimum options. Fig. 1 shows the distribution of the hedging errors in the monthly case: the peak corresponding to -4.28 is clearly visible as it is the heavy left tail for the dynamic hedge. The amount of residual risk inherent to the different kinds of hedging is largely dependent on the chosen risk measure: the risk of a dynamic hedging strategy is very low if revisions are performed semiweekly, but there are cases in which the static hedge outperforms the dynamical counterpart.

Table 4

Sample statistics of the replication error of different hedging strategies, based on 1000 simulations. In detail, we provide sample $\mathrm{VaR}_{\alpha}$ and $\mathrm{ES}_{\alpha}$ for $\alpha=0.01$ and 0.05

\begin{tabular}{lclll}
\hline & $\begin{array}{l}\text { Dynamic } \\
\text { (monthly) }\end{array}$ & $\begin{array}{l}\text { Dynamic } \\
\text { (weekly) }\end{array}$ & $\begin{array}{l}\text { Dynamic } \\
\text { (semi- } \\
\text { weekly) }\end{array}$ & Static \\
\hline $\mathrm{VaR}_{0.01}$ & -18.92 & -5.30 & -4.26 & -4.28 \\
$\mathrm{VaR}_{0.05}$ & -8.21 & -4.01 & -2.65 & -4.28 \\
$\mathrm{ES}_{0.01}$ & -26.79 & -6.34 & -5.46 & -4.28 \\
$\mathrm{ES}_{0.05}$ & -14.39 & -4.83 & -3.69 & -4.28 \\
Mean & -0.26 & 0.36 & -0.02 & -0.05 \\
$\mathrm{SD}$ & 5.60 & 3.20 & 1.59 & 4.58 \\
\hline
\end{tabular}




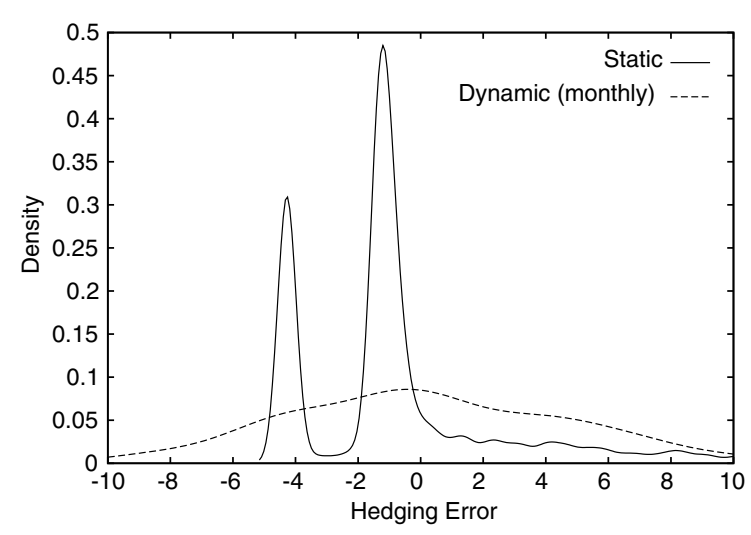

Fig. 1. Hedging error density (kernel estimated) for static and monthly revised delta-based portfolio.

We finally examine a 7-dimensional portfolio option, first presented in Milevsky and Posner (1998a), and priced by MMC in Pellizzari (2001). Transaction costs are accounted for, assuming different percentage fees. This option, embedded in a an Index-Linked Guaranteed Investment Cer- tificate (ILGIC), is written on a weighted sum of several major stock indices, namely TSE100 (Canada), CAC40 (France), DAX (Germany), MIB30 (Italy), Nikkei225 (Japan), FTSE100 (UK) and S\&P500 (USA). An ILGIC is sold with various maturities (1, 3, 5 and 10 years) and we refer the reader to the above mentioned papers and to Milevsky and Posner (1998b) for more details and full parameter list. We feel that this example is well suited to explore the practical problems in hedging long-lived derivatives and to explore if static methods can be useful for hedging purposes.

In order to estimate the replication error of a hedging strategy we simulate one thousand 7dimensional paths and look at $\mathrm{VaR}$ and $\mathrm{ES}$ at confidence level $1 \%$ and $5 \%$. We consider $6,12,60$ and 120 rebalancings per year, roughly equivalent to one revision every two months $(2 \mathrm{M})$, every month (M), every week (W) and twice a week (W/2). We also take into account proportional transaction costs: in order to rebalance at time $t+1$ the portfolio quotas from $\mathbf{b}_{t}$ to $\mathbf{b}_{t+1}$, the transaction costs

Table 5

Replication error risk measures for a 1 year maturity ILGIC, with estimated standard deviations in brackets

\begin{tabular}{|c|c|c|c|c|c|c|c|c|}
\hline \multirow{3}{*}{$\begin{array}{l}\text { Transaction } \\
\text { cost }\end{array}$} & \multicolumn{8}{|c|}{ Maturity: $T=1$, price: 0.0590 (Rebalancing frequency) } \\
\hline & \multicolumn{4}{|l|}{$\mathrm{VaR}_{0.01}$} & \multicolumn{4}{|l|}{$\mathrm{VaR}_{0.05}$} \\
\hline & $2 \mathrm{M}$ & $\mathrm{M}$ & $\mathrm{W}$ & $\mathrm{W} / 2$ & $2 \mathrm{M}$ & $\mathrm{M}$ & $\mathrm{W}$ & $\mathrm{W} / 2$ \\
\hline$v=0$ & $\begin{array}{l}-0.0460 \\
(0.0041)\end{array}$ & $\begin{array}{l}-0.0295 \\
(0.0029)\end{array}$ & $\begin{array}{l}-0.0122 \\
(0.0008)\end{array}$ & $\begin{array}{l}-0.0085 \\
(0.0006)\end{array}$ & $\begin{array}{l}-0.0247 \\
(0.0022)\end{array}$ & $\begin{array}{l}-0.0189 \\
(0.0010)\end{array}$ & $\begin{array}{l}-0.0079 \\
(0.0004)\end{array}$ & $\begin{array}{l}-0.0045 \\
(0.0002)\end{array}$ \\
\hline$v=0.001$ & $\begin{array}{l}-0.0474 \\
(0.0042)\end{array}$ & $\begin{array}{l}-0.0316 \\
(0.0027)\end{array}$ & $\begin{array}{l}-0.0172 \\
(0.0010)\end{array}$ & $\begin{array}{l}-0.0155 \\
(0.0007)\end{array}$ & $\begin{array}{l}-0.0261 \\
(0.0020)\end{array}$ & $\begin{array}{l}-0.0209 \\
(0.0009)\end{array}$ & $\begin{array}{r}-0.0120 \\
(0.0006)\end{array}$ & $\begin{array}{l}-0.0104 \\
(0.0003)\end{array}$ \\
\hline$v=0.002$ & $\begin{array}{l}-0.0489 \\
(0.0044)\end{array}$ & $\begin{array}{l}-0.0338 \\
(0.0031)\end{array}$ & $\begin{array}{l}-0.0223 \\
(0.0010)\end{array}$ & $\begin{array}{l}-0.0225 \\
(0.0008)\end{array}$ & $\begin{array}{c}-0.0276 \\
(0.0020)\end{array}$ & $\begin{array}{l}-0.0227 \\
(0.0009)\end{array}$ & $\begin{array}{r}-0.0165 \\
(0.0007)\end{array}$ & $\begin{array}{r}-0.0165 \\
(0.0004)\end{array}$ \\
\hline$v=0.004$ & $\begin{array}{l}-0.0518 \\
(0.0044)\end{array}$ & $\begin{array}{l}-0.0382 \\
(0.0033)\end{array}$ & $\begin{array}{l}-0.0311 \\
(0.0013)\end{array}$ & $\begin{array}{l}-0.0366 \\
(0.0009)\end{array}$ & $\begin{array}{l}-0.0312 \\
(0.0020)\end{array}$ & $\begin{array}{l}-0.0268 \\
(0.0009)\end{array}$ & $\begin{array}{l}-0.0253 \\
(0.0008)\end{array}$ & $\begin{array}{l}-0.0293 \\
(0.0008)\end{array}$ \\
\hline Static & \multicolumn{4}{|c|}{$-0.0366(0.0019)$} & \multicolumn{4}{|c|}{$-0.0287(0.0008)$} \\
\hline$v=0$ & $\begin{array}{l}-0.0596 \\
(0.0053)\end{array}$ & $\begin{array}{l}-0.0380 \\
(0.0028)\end{array}$ & $\begin{array}{l}-0.0172 \\
(0.0023)\end{array}$ & $\begin{array}{l}-0.0109 \\
(0.0012)\end{array}$ & $\begin{array}{l}-0.0382 \\
(0.0022)\end{array}$ & $\begin{array}{l}-0.0259 \\
(0.0015)\end{array}$ & $\begin{array}{l}-0.0112 \\
(0.0008)\end{array}$ & $\begin{array}{r}-0.0070 \\
(0.0005)\end{array}$ \\
\hline$v=0.001$ & $\begin{array}{l}-0.0613 \\
(0.0049)\end{array}$ & $\begin{array}{l}-0.0404 \\
(0.0030)\end{array}$ & $\begin{array}{l}-0.0218 \\
(0.0019)\end{array}$ & $\begin{array}{c}-0.0178 \\
(0.0011)\end{array}$ & $\begin{array}{l}-0.0399 \\
(0.0028)\end{array}$ & $\begin{array}{c}-0.0282 \\
(0.0014)\end{array}$ & $\begin{array}{l}-0.0157 \\
(0.0008)\end{array}$ & $\begin{array}{l}-0.0133 \\
(0.0006)\end{array}$ \\
\hline$v=0.002$ & $\begin{array}{l}-0.0630 \\
(0.0051)\end{array}$ & $\begin{array}{l}-0.0429 \\
(0.0028)\end{array}$ & $\begin{array}{l}-0.0267 \\
(0.0023)\end{array}$ & $\begin{array}{l}-0.0248 \\
(0.0010)\end{array}$ & $\begin{array}{l}-0.0415 \\
(0.0027)\end{array}$ & $\begin{array}{l}-0.0304 \\
(0.0014)\end{array}$ & $\begin{array}{c}-0.0204 \\
(0.0008)\end{array}$ & $\begin{array}{l}-0.0200 \\
(0.0006)\end{array}$ \\
\hline$v=0.004$ & $\begin{array}{l}-0.0663 \\
(0.0054)\end{array}$ & $\begin{array}{l}-0.0479 \\
(0.0026)\end{array}$ & $\begin{array}{l}-0.0366 \\
(0.0020)\end{array}$ & $\begin{array}{l}-0.0392 \\
(0.0011)\end{array}$ & $\begin{array}{l}-0.0448 \\
(0.0026)\end{array}$ & $\begin{array}{l}-0.0350 \\
(0.0015)\end{array}$ & $\begin{array}{l}-0.0299 \\
(0.0009)\end{array}$ & $\begin{array}{l}-0.0335 \\
(0.0007)\end{array}$ \\
\hline Static & \multicolumn{4}{|c|}{$-0.0410(0.0019)$} & \multicolumn{4}{|c|}{$-0.0329(0.0009)$} \\
\hline
\end{tabular}

The rebalancing frequencies reported are two months (2M), one month (M), one week (W) and half-week (W/2). Standard deviations are shown in brackets. 
$v \sum_{i=1}^{7}\left|b_{i t}-b_{i(t+1)}\right| S_{i(t+1)}$

must be paid. We assume there are no costs to manage the riskfree account and the commission rates $v=0,0.001,0.002,0.004$ to be somehow representative of typical costs (many online brokers, for example, offer $v=0.2 \%$ ). The deltas for the dynamic hedging portfolios are calculated using 1024 correlated simulations, as in the previous example. The static hedging portfolio is build at $t=0$ and is composed of 7 at-the-money call options.

To save space we focus only on the two extreme maturities, 1 and 10 years: the results relative to 3 and 5 years maturities are available on request and do not alter in any substantial way the following considerations. Tables 5 and 6 show the Values at Risk (VaR) and the Expected Shortfalls (ES) of 1 and 10 years maturity ILGICs if dynamic or static hedges are used (with various rebalancing frequencies and commission rates). For example, the lower left part of Table 5 shows that if $v=0.2 \%$ then the expected shortfalls (at 1\% level) of the dynamic hedging strategies are respectively $-0.0630,-0.0429,-0.0267$, and -0.0248 for different rebalancing intervals. We also see that the static hedging produces an ES of -0.041 . The standard deviations are reported in brackets and have been computed using 100 bootstrap replicates. In the vast majority of cases, the standard deviations are quite low and rarely exceed $10 \%$ of the risk measures.

Observe preliminarily that many of the entries in the tables are a sizeable fraction of the price of the derivatives and sometimes even exceed them, thus pointing to massive residual risk even if hedging was carefully performed. This is in substantial agreement, for example, to figures reported in Green and Figlewsky (1999) for the univariate case.

Table 6

Replication error risk measures for a 10 years maturity ILGIC, with estimated standard deviations in brackets

\begin{tabular}{|c|c|c|c|c|c|c|c|c|}
\hline \multirow{3}{*}{$\begin{array}{l}\text { Transaction } \\
\text { cost }\end{array}$} & \multicolumn{8}{|c|}{ Maturity: $T=10$, price: 0.3113 (Rebalancing frequency) } \\
\hline & \multicolumn{4}{|l|}{$\mathrm{VaR}_{0.01}$} & \multicolumn{4}{|l|}{$\mathrm{VaR}_{0.05}$} \\
\hline & $2 \mathrm{M}$ & M & $\mathrm{W}$ & $\mathrm{W} / 2$ & $2 \mathrm{M}$ & M & $\mathrm{W}$ & $\mathrm{W} / 2$ \\
\hline$v=0$ & $\begin{array}{l}-0.0246 \\
(0.0013)\end{array}$ & $\begin{array}{l}-0.0226 \\
(0.0021)\end{array}$ & $\begin{array}{l}-0.0135 \\
(0.0005)\end{array}$ & $\begin{array}{l}-0.0145 \\
(0.0008)\end{array}$ & $\begin{array}{l}-0.0198 \\
(0.0003)\end{array}$ & $\begin{array}{l}-0.0146 \\
(0.0003)\end{array}$ & $\begin{array}{l}-0.0093 \\
(0.0003)\end{array}$ & $\begin{array}{r}-0.0099 \\
(0.0003)\end{array}$ \\
\hline$v=0.001$ & $\begin{array}{l}-0.0288 \\
(0.0013)\end{array}$ & $\begin{array}{l}-0.0295 \\
(0.0028)\end{array}$ & $\begin{array}{l}-0.0295 \\
(0.0008)\end{array}$ & $\begin{array}{l}-0.0471 \\
(0.0011)\end{array}$ & $\begin{array}{l}-0.0232 \\
(0.0002)\end{array}$ & $\begin{array}{l}-0.0191 \\
(0.0002)\end{array}$ & $\begin{array}{l}-0.0253 \\
(0.0002)\end{array}$ & $\begin{array}{l}-0.0403 \\
(0.0002)\end{array}$ \\
\hline$v=0.002$ & $\begin{array}{l}-0.0339 \\
(0.0017)\end{array}$ & $\begin{array}{l}-0.0355 \\
(0.0028)\end{array}$ & $\begin{array}{l}-0.0469 \\
(0.0009)\end{array}$ & $\begin{array}{l}-0.0830 \\
(0.0018)\end{array}$ & $\begin{array}{l}-0.0265 \\
(0.0003)\end{array}$ & $\begin{array}{l}-0.0238 \\
(0.0003)\end{array}$ & $\begin{array}{l}-0.0417 \\
(0.0003)\end{array}$ & $\begin{array}{l}-0.0725 \\
(0.0003)\end{array}$ \\
\hline$v=0.004$ & $\begin{array}{l}-0.0439 \\
(0.0019)\end{array}$ & $\begin{array}{l}-0.0486 \\
(0.0039)\end{array}$ & $\begin{array}{l}-0.0851 \\
(0.0014)\end{array}$ & $\begin{array}{l}-0.1560 \\
(0.0025)\end{array}$ & $\begin{array}{l}-0.0338 \\
(0.0003)\end{array}$ & $\begin{array}{l}-0.0341 \\
(0.0002)\end{array}$ & $\begin{array}{l}-0.0763 \\
(0.0002)\end{array}$ & $\begin{array}{l}-0.1383 \\
(0.0004)\end{array}$ \\
\hline Static & \multicolumn{4}{|c|}{$-0.0859(0.0031)$} & \multicolumn{4}{|c|}{$-0.0709(0.0015)$} \\
\hline$v=0$ & $\begin{array}{l}-0.0299 \\
(0.0017)\end{array}$ & $\begin{array}{l}-0.0331 \\
(0.0056)\end{array}$ & $\begin{array}{l}-0.0153 \\
(0.0008)\end{array}$ & $\begin{array}{l}-0.0170 \\
(0.0010)\end{array}$ & $\begin{array}{l}-0.0238 \\
(0.0008)\end{array}$ & $\begin{array}{l}-0.0201 \\
(0.0018)\end{array}$ & $\begin{array}{l}-0.0121 \\
(0.0005)\end{array}$ & $\begin{array}{l}-0.0128 \\
(0.0005)\end{array}$ \\
\hline$v=0.00$ & $\begin{array}{l}-0.0342 \\
(0.0018)\end{array}$ & $\begin{array}{c}-0.0404 \\
(0.0062)\end{array}$ & $\begin{array}{l}-0.0319 \\
(0.0008)\end{array}$ & $\begin{array}{l}-0.0505 \\
(0.0013)\end{array}$ & $\begin{array}{l}-0.0277 \\
(0.0008)\end{array}$ & $\begin{array}{l}-0.0257 \\
(0.0018)\end{array}$ & $\begin{array}{l}-0.0280 \\
(0.0005)\end{array}$ & $\begin{array}{l}-0.0445 \\
(0.0007)\end{array}$ \\
\hline$v=0.002$ & $\begin{array}{l}-0.0386 \\
(0.0017)\end{array}$ & $\begin{array}{l}-0.0478 \\
(0.0069)\end{array}$ & $\begin{array}{l}-0.0501 \\
(0.0012)\end{array}$ & $\begin{array}{l}-0.0868 \\
(0.0014)\end{array}$ & $\begin{array}{l}-0.0316 \\
(0.0009)\end{array}$ & $\begin{array}{l}-0.0315 \\
(0.0019)\end{array}$ & $\begin{array}{l}-0.0452 \\
(0.0006)\end{array}$ & $\begin{array}{c}-0.0784 \\
(0.0010)\end{array}$ \\
\hline$v=0.004$ & $\begin{array}{l}-0.0480 \\
(0.0016)\end{array}$ & $\begin{array}{l}-0.0626 \\
(0.0070)\end{array}$ & $\begin{array}{l}-0.0892 \\
(0.0014)\end{array}$ & $\begin{array}{l}-0.1632 \\
(0.0024)\end{array}$ & $\begin{array}{l}-0.0397 \\
(0.0011)\end{array}$ & $\begin{array}{l}-0.0434 \\
(0.0021)\end{array}$ & $\begin{array}{l}-0.0821 \\
(0.0010)\end{array}$ & $\begin{array}{l}-0.1487 \\
(0.0019)\end{array}$ \\
\hline Static & \multicolumn{4}{|c|}{$-0.0935(0.0012)$} & \multicolumn{4}{|c|}{$-0.0802(0.0015)$} \\
\hline
\end{tabular}

The rebalancing frequencies reported are two months (2M), one month (M), one week (W) and half-week (W/2). Standard deviations are shown in brackets. 

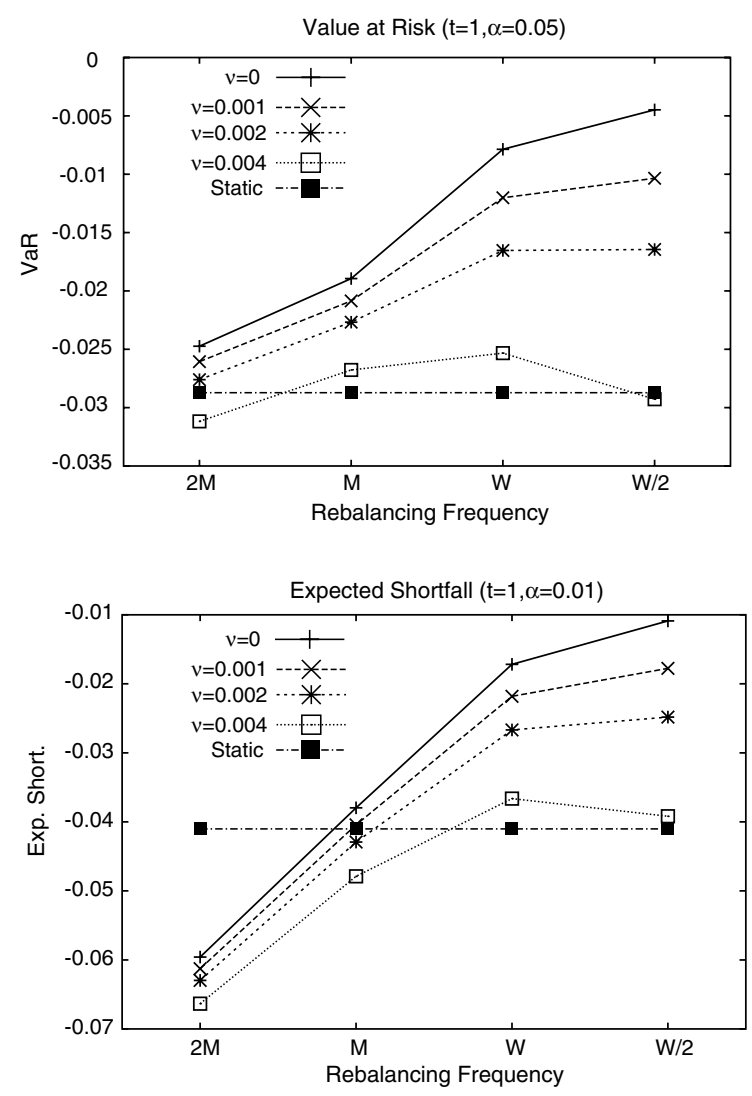

Fig. 2. VaR and ES measures for a 1 year maturity ILGIC. The panels show $\mathrm{VaR}_{0.05}$ and $\mathrm{ES}_{0.01}$ for dynamic and static hedging corresponding to various transaction rates.

The analysis of Table 5 is eased looking at Fig. 2 that depicts the upper right and lower left parts of the table. A visual comparison is justified by the relatively small standard deviations of the estimates and is useful to understand at a glance the many entries of Tables 5 and 6 .

It can be seen in the first exhibit of Fig. 2 that an increment of the rebalancing frequency is generally beneficial, with the exception of the $v=0.004$ case that shows that it is not convenient to revise too often the hedge in the presence of relatively high transaction costs. A visible flattening occurs for $v=0.002$ too and there is not much difference between weekly and semiweekly revisions with this commission rate. The static hedging is represented by the horizontal line in the graph and we observe that it is roughly equivalent to dynamic hedging (no matter of $v$ ) for $2 \mathrm{M}$ revisions, while it is generally riskier for other frequencies (but again this does not hold when $v=0.004$ ).

The previous consideration are strengthened observing the second exhibit of Fig. 2, depicting expected shortfall at 1\% confidence level. The static hedging portfolio achieves roughly the same performances of the dynamic hedges with monthly revisions and, in particular, it is at least as good as the dynamic strategy when $v=0.004$.

As pointed out by a referee, it is interesting and of practical importance to compare the sensitivity of the performance of dynamic and static hedges if volatilities move. There are countless ways to perturb the volatility structure of a multivariate claim (think, for example, to one-time shocks or changes in the level of some $\sigma$ 's). Hence, with no hope to be exhaustive, the upper (lower) panel of Fig. 3 shows the $\mathrm{VaR}_{0.05}$ and $\mathrm{ES}_{0.01}$ of static and dynamic hedges for the shortest maturity ILGIC if all the volatilities $\sigma_{1}, \ldots, \sigma_{7}$ increase linearly by $25 \%$ over the lifespan of the claim (1 year). We feel that this resembles a typical situation where the overall volatility of the market starts moving just after the option has been written, altering the exante expectations of the issuer that is neverthelees binded to the contract. The comparison of Figs. 2 and 3 shows that the risk of the static hedging strategy is remarkably insensitive to moving volatilities (indeed, the VaRs in the two figures differ by $10^{-3}$ while ES moves from -0.0410 to -0.0444 ). On the contrary, a smooth increase in volatilities inflates considerably the risk of a dynamic hedging strategy, that is to be preferred only if frequent revisions are performed with very low transaction costs.

Fig. 4 shows the $\mathrm{VaR}_{0.01}$ and $\mathrm{ES}_{0.05}$ for the long maturity (10 years) ILGIC, depicting the upper left and lower right parts of Table 6 . The plots are quite similar and illustrate that dynamic hedging reduces risk much more than static hedging if low revision frequencies are selected and very low cost are charged. However, there is no real advantage to rebalance more often than every two months, perhaps with the exception of the case of no transaction costs. This can be understood in view of the fact that the long maturity comes together with many revisions that might be imprecise due to 

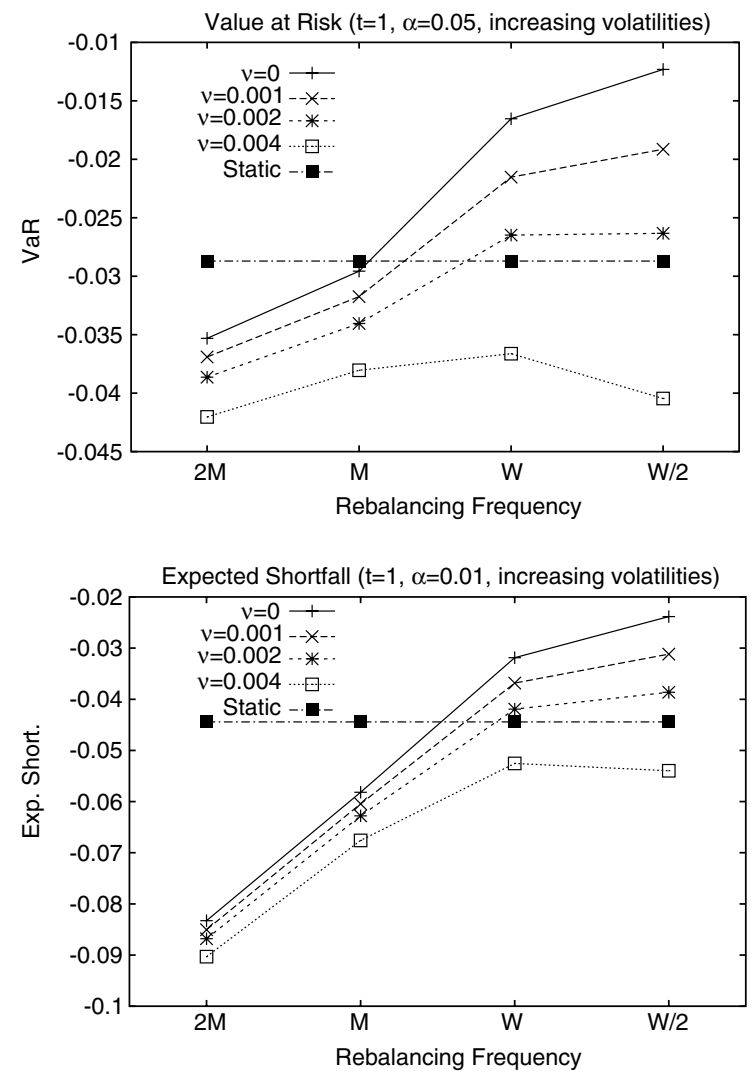

Fig. 3. VaR and ES of a 1 year maturity ILGIC, for static and dynamic hedgings corresponding to different transaction rates. We assume that the volatilities of the assets is linearly increasing by $25 \%$ during the lifespan of the option.

discretization and/or numeric greeks calculation. Hence the replication error at maturity is adversely influenced by revision frequency. As far as the weak results of static hedging are concerned, note that this is an extreme case in which one portfolio is held for 10 years with no modification. It can be conjectured (and the examples in this paper support this point) that static portfolios can better cope with short to medium maturities, say less than a year.

\section{Conclusion}

This paper presents an alternative hedging method, based on an approximate replication of a multivariate derivative using a portfolio of simple
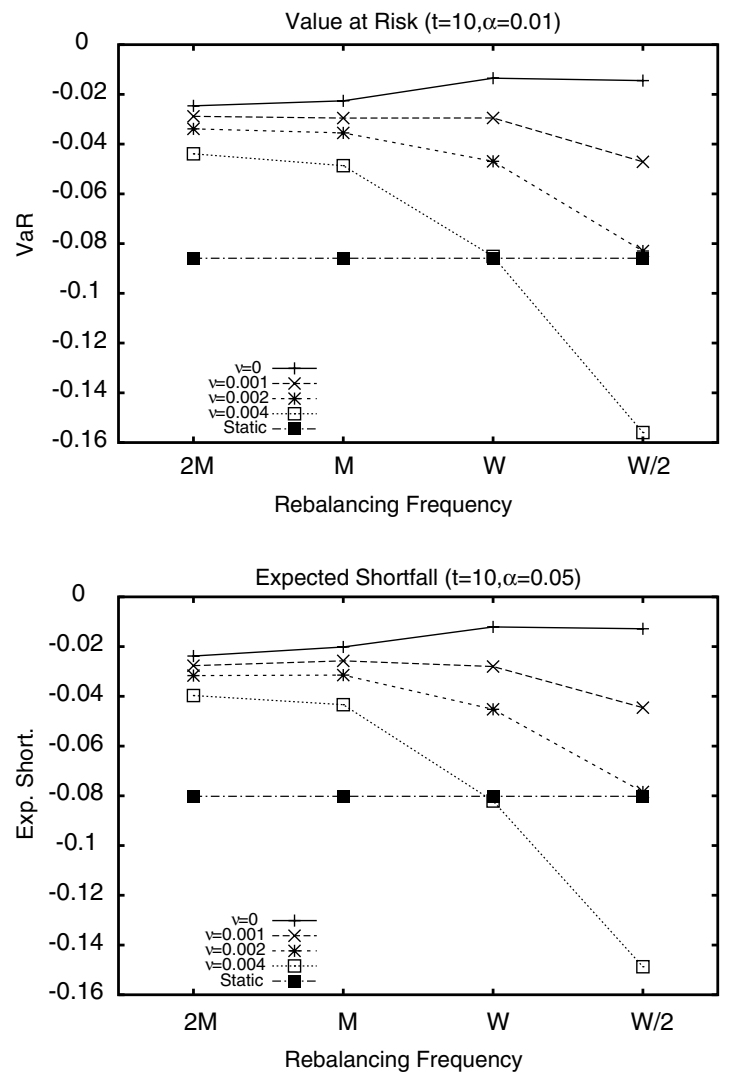

Fig. 4. VaR and ES measures for a 10 years maturity ILGIC. The panels show $\mathrm{VaR}_{0.01}$ and $\mathrm{ES}_{0.05}$ for dynamic and static hedging corresponding to various transaction rates.

options. The risk resulting from writing an option is not totally removed, but the same can be said for standard BS dynamic hedging, that is perfect only in the limit of continuous rebalancings and no friction. Many papers have shown that practical implementations of BS hedging strategy can expose the writer to substantial residual risk. Among the advantages of the static hedging procedure there are conceptual simplicity and easy implementation, negligible transaction costs and flexibility: the method can for example be tailored to the assets available in the market and provides different approximate hedging portfolio depending on various situations (like budget constraints, or no short selling requirements).

At a higher level of abstraction, the method generalizes and casts further light on a variance 
reduction $\mathrm{MC}$ scheme recently proposed and known as mean Monte Carlo. This interpretation ensures that increasing the number of 'simulations' produces more accurate pricing results (though the residual risk obviously remains bounded away from zero).

The potential of the proposed technique is assessed pricing some bivariate max options studied in Boyle (1988): the results are fairly accurate using only 1000 simulations and each price is supported by a viable static hedging strategy, that reduces but does not fully eliminate risk. Analysis of portfolio options written on 2 and 7 assets shows that the residual risk of static hedging is in general bigger than the one obtained by a dynamic hedging. However, if transaction costs are relevant or rebalacing frequency unappropriate, the risk figures produced by the two methods are comparable.

\section{Acknowledgements}

We thank S. Hodges, FORC, University of Warwick, and C. Pizzi, Department of Statistics, University of Venice, for useful discussions. I am grateful to the participants to seminars held at Universities of Pisa, Venice, Verona and to the AMASES 2001 meeting in Florence. I am indebted to three referees who provided very useful remarks and bibliographic references.

\section{References}

Ahn, H., Muni, A., Swindle, G., 1997. Misspecified asset price models and robust hedging strategies. Applied Mathematical Finance 4, 21-36.

Avellaneda, M., Buff, R., Friedman, C., Grandechamp, N., Kruk, L., Newman, J., 2000. Weighted Monte Carlo: A new technique for calibrating asset-pricing models. International Journal of Theoretical and Applied Finance 4, 91119.

Ben Ameur, H., Breton, M., L'Ecuyer, P., 2001. Partial hedging for options based on extreme values and passage times. In: Zaccour, G. (Ed.), Decisions and Control in Management Science. Kluwer Academic Publishers.
Boyle, P., 1988. A lattice framework for option pricing with two state variables. Journal of Financial and Quantitative Analysis 23 (1), 1-12.

Boyle, P., Emanuel, D., 1980. Discretely adjusted option hedges. Journal of Financial Economics 8, 259-282.

Bratley, P., Fox, B., Schrage, L., 1987. A Guide to Simulation. Springer-Verlag.

Carr, P., Ellis, K., Gupta, V., 1998. Static hedging of exotic options. Journal of Finance LIII (3), 1165-1190.

Derman, E., Ergener, D., Kani, I., 1995. Static option replication. Journal of Derivatives (Summer), 78-95.

Follmer, H., Leukert, P., 1999. Quantile hedging. Finance and Stochastics 3, 251-273.

Follmer, H., Leukert, P., 2000. Efficient hedging: Cost versus shortfall risk. Finance and Stochastics 4, 117-146.

Green, C., Figlewsky, S., 1999. Market risk and model risk for a financial institution writing options. Journal of Finance LIV (4), 1465-1499.

Kabanov, Y., Safarian, M., 1997. On Leland's strategy of option pricing with transactions costs. Finance and Stochastics 1, 239-250.

Krommer, A., Ueberhuber, C., 1998. Computational Integration. SIAM, Philadelphia.

Lavenberg, S., Welch, P., 1981. A perspective on the use of control variables to increase the efficiency of Monte Carlo simulations. Management Science 27, 322-335.

Leland, H., 1985. Option pricing and replication with transactions costs. Journal of Finance XL (5), 1283-1301.

Milevsky, M., Posner, S., 1998a. A closed-form approximation for valuing basket options. Journal of Derivatives (Summer), 54-62.

Milevsky, M., Posner, S., 1998b. Erratum to a closed-form approximation for valuing basket options. Journal of Derivatives (Winter), 83.

Nelson, B., 1990. Control variate remedies. Operations Research 38, 974-992.

Pellizzari, P., 2001. Efficient Monte Carlo pricing of European options using mean value control variates. Decision in Economics and Finance 24, 107-126.

Rebonato, R., Cooper, I., 1998. Coupling backward induction with Monte Carlo simulations: A fast Fourier transform (FFT) approach. Applied Mathematical Finance 5, 131141.

Rubinstein, R., 1981. Simulation and the Monte Carlo Method. Wiley, New York.

Schmeiser, B., Taafe, M., Wang, J. Control-variate estimation using estimated control means. IIE Transactions, forthcoming.

Stulz, R., 1982. Options on the minimum or the maximum of two risky assets: Analysis and applications. Journal of Financial Economics 10, 161-185.

Szechtman, R., Glynn, P., 2001. Constrained Monte Carlo and the method of control variates. In: Proceedings of the 2001 Winter Simulation Conference, pp. 379-384. 